\title{
Ionospheric precursors for crustal earthquakes in Italy
}

\author{
L. Perrone ${ }^{1}$, L. P. Korsunova ${ }^{2}$, and A. V. Mikhailov ${ }^{2}$ \\ ${ }^{1}$ Istituto Nazionale di Geofisica e Vulcanologia, Via di Vigna Murata 605, Rome 00143, Italy \\ ${ }^{2}$ Pushkov Institute of Terrestrial Magnetism, Ionosphere and Radio Wave Propagation (IZMIRAN), Troitsk, Moscow Region \\ 142190, Russia
}

Received: 31 July 2009 - Revised: 11 March 2010 - Accepted: 5 April 2010 - Published: 12 April 2010

\begin{abstract}
Crustal earthquakes with magnitude $6.0>\mathrm{M} \geq 5.5$ observed in Italy for the period 1979-2009 including the last one at L'Aquila on 6 April 2009 were considered to check if the earlier obtained relationships for ionospheric precursors for strong Japanese earthquakes are valid for the Italian moderate earthquakes. The ionospheric precursors are based on the observed variations of the sporadic E-layer parameters ( $\left.h^{\prime} \mathrm{Es}, f b \mathrm{Es}\right)$ and $f o \mathrm{~F} 2$ at the ionospheric station Rome. Empirical dependencies for the seismo-ionospheric disturbances relating the earthquake magnitude and the epicenter distance are obtained and they have been shown to be similar to those obtained earlier for Japanese earthquakes. The dependences indicate the process of spreading the disturbance from the epicenter towards periphery during the earthquake preparation process. Large lead times for the precursor occurrence (up to 34 days for $\mathrm{M}=5.8-5.9$ ) tells about a prolong preparation period. A possibility of using the obtained relationships for the earthquakes prediction is discussed.
\end{abstract}

Keywords. Ionosphere (Ionospheric disturbances; Ionospheric irregularities; General or miscellaneous)

\section{Introduction}

Ground observations of various geophysical parameters for the periods preceding the earthquakes revealed some of them which can be used as the earthquake precursors. The anomalies in these parameter variations can be registered up to one month in advance (middle-term precursors) as well as with lead times from some hours up to one day (shortterm precursors) (Gufeld and Gusev, 1998). Both electric and electro-magnetic effects often precede the earthquakes (e.g. Hayakawa, 1999; Bolt, 1999; Freund, 2000; Hayakawa

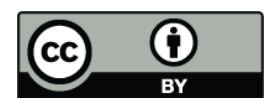

Correspondence to: L. Perrone (loredana.perrone@ingv.it) and Molchanov, 2002). Although many mechanisms for the earthquake precursor occurrence have been proposed (see a special issue by Hayakawa et al., 2006, for recent progress in this area), the researchers are still far from the understanding of these relationships. For instance, a thorough analysis of the association between earthquakes and Pc1 pulsations (Bortnik et al., 2008) has revealed an enhanced occurrence probability of Pc1 pulsations 5-15 days in advance of the earthquakes, during the daytime. This relationship was shown to be statistically significant. But only $2 / 3$ of pulsations were followed by at least one earthquake event, a roughly similar fraction of earthquake events (274 of 434) were preceded by at least one pulsation. Along with this they have obtained an important and interesting result - the absence of any significant association between earthquakes and geomagnetic activity despite the other concept saying that such relationship exists (Mazzarella and Palumbo, 1988; Yanben et al., 2004).

Seismo-ionospheric relationships are widely discussed in recent publications (Strakhov et al., 1999; Ondoh, 2003, 2009; Trigunait et al., 2004; Hobara and Parrot, 2005; Liu et al., 2006; Sharma et al., 2006; Maekawa et al., 2006; Ondoh and Hayakawa, 2006; Dabas et al., 2007). Various ionospheric parameters are considered: F2-layer critical frequency $f o \mathrm{~F} 2$, total electron content TEC, electron temperature Te at F2-layer heights, LF radio signals. The degree of reliability for the revealed associations is different in different analyses.

Statistically significant results based on 5-year observations of LF signals (wave path length of $770 \mathrm{~km}$ ) were obtained in Japan (Maekawa et al., 2006). An effective magnitude Meff as the integral impact of all earthquakes in sensitive area for a current day was used in their study. It has been shown that the ionosphere is definitely disturbed in terms of both amplitude and dispersion of the signals and these perturbations tend to take place prior to an earthquake. 
The amplitude decreases by $\sim 3 \mathrm{~dB}$ and the dispersion significantly enhances one week to a few days before the earthquake with $\mathrm{M}_{\mathrm{eff}} \geq 6.0$. Such changes in both amplitude and dispersion exceed the $2 \sigma$ criterion, indicating the statistical significance.

An attempt to find an association between earthquakes and electron temperature Te in the topside low-latitude ionosphere was undertaken by Sharma et al. (2006). Although in 6 cases considered a 20-25\% increase in Te has been observed, the results do not seem convincing. On one hand, it is a well-know problem to specify an undisturbed background level using satellite observations. On the other hand, relatively weak earthquakes with $\mathrm{M} \leq 5$ were considered. According to other publications noticeable ionospheric effects in the F2-region are not expected under weak earthquakes and such relatively small deviations in Te may result from other reasons. Electron temperature is known to be closely related to electron concentration in the F2-region, and the latter in its turn is strongly affected by electric fields, which are very variable in the low-latitude ionosphere even under quiet geomagnetic activity. However, these questions are not discussed by Sharma et al. (2006).

Variations of $f_{o} \mathrm{~F} 2$ during seismo-active periods are considered in many papers, as $f o \mathrm{~F} 2$ observations are usually available from ground-based ionosondes. Two papers in the row should be mentioned. A reaction to an isolated and very powerful Hachinohe earthquake with $\mathrm{M}=8.3$ has been analyzed by Hobara and Parrot (2005) using foF2 observations on the ionosonde stations in Asian longitudinal sector, some of the stations being very close to the epicenter $(40.8 \mathrm{~N}$; 143.2 E). A foF 2 decrease down to $3 \mathrm{MHz} 4$ days prior the event and in 2 days after the earthquake have been observed. The effect took place in the course of one day only and maximized in the afternoon (15:00 LT) hours. The $f o \mathrm{~F} 2$ decrease was registered in the vicinity to the epicenter and not further than $1500 \mathrm{~km}$ apart. In this case we have a pronounced ionospheric reaction to the event. As the formation mechanism of the mid-latitude daytime F2-layer is well-known, an additional analysis of that and similar events may help understand physical processes responsible for the observed $f o \mathrm{~F} 2$ variations. A decrease of $f o \mathrm{~F} 2$ from its monthly median at Wakkanai was observed within \pm 3 days around the strong earthquake with $M=7.8$ in Japan (Ondoh, 1998, 2000).

Liu et al. (2006) have analyzed the association between foF 2 and 184 earthquakes with $\mathrm{M} \geq 5.0$ took place during 1994-1999 in the Taiwan area. The results of their statistical analysis coincide with the $f o \mathrm{~F} 2$ effects observed during the above mentioned very strong earthquake - a decrease in $f o \mathrm{~F} 2$ by $>25 \%$ during the afternoon (12:00-18:00 LT) period significantly occurs within 5 days before the earthquake. The effect increases with the earthquake magnitude but decreases with the distance from the epicenter to the ionospheric station. However, only the $\mathrm{M} \geq 5.4$ earthquakes have a significant chance to result in a pronounced $f_{o} \mathrm{~F} 2$ decrease and only those of them which were within the distance of $150 \mathrm{~km}$.
Sporadic Es parameters: its occurrence probability and the frequency increase in the semi-transparency range have been considered by Silina et al. (2001). Ondoh (2003), Ondoh and Hayakawa (2006) have observed an anomalous foEs increase on some Japanese ionosonde stations close in time to a strong earthquake with $\mathrm{M}=7.2$.

In general, one may conclude that analyses of seismoionospheric relationships are performed at the level of looking for a correlation (yes/no) under various time lags using the only criterion - a statistical significance of the relationship revealed. However, the formation mechanisms of shortterm, middle-term, and long-term earthquake precursors may be different and the corresponding ionospheric effects may be also different. Therefore, one may think that the revealed $f o \mathrm{~F} 2$ decrease within 5 days before the earthquakes is typical of the short-term precursors while the aim of our paper is to find middle-term ionospheric precursors.

Any attempt to obtain a qualitative relationship for seismoionospheric precursors should be considered as an important step towards the understanding of physical mechanism of such relationships. For instance, Liu et al. (2006) have found the expressions relating the probability of the earthquake to result in $>25 \%$ fo $\mathrm{F} 2$ decrease with the earthquake magnitude and the distance between the earthquake epicenter and the ionospheric station.

The approach being developed by Korsunova and Khegai (2006, 2008) may be considered as a successful step in this direction. The idea of their approach is based on the results of a theoretical analysis by Kim et al. $(1993,1994)$, who have shown that electric field above the preparation zone of future earthquake can penetrate into the ionosphere to form a dense sporadic Es layer at $120-140 \mathrm{~km}$ heights. Therefore the basic feature of this mechanism is the formation of high Es layer due to penetrating electric field rather than the wind shear mechanism forming usual sporadic Es. Korsunova and Khegai $(2006,2008)$ have shown that for strong $(M>6.5)$ crustal earthquakes observed in Japan, the deviations of ionospheric parameters from the background level can be related to the magnitude and the epicenter distance of the corresponding earthquake. The obtained dependence for $\log (\Delta T \cdot R)$ tells about a decrease of the lead time $\Delta T$ with a corresponding increase of the epicenter distance $\mathrm{R}$ from the ionospheric station. This tells about spreading of the seismo-ionospheric disturbance from the epicenter area towards periphery. Earlier similar dependencies were obtained for geophysical parameters measured at the ground level (Sidorin, 1992).

A new feature of the Korsunova and Khegai $(2006,2008)$ method is in simultaneous taking into account the variations of sporadic Es and regular F2 layers. The occurrence of abnormally high Es layer with $\Delta h^{\prime} \mathrm{Es} \geq 10 \mathrm{~km}$ is considered followed by an increase in the blanketing frequency $f b E s$ and in $f o F 2$. The ionosphere reaction was shown to be related to the magnitude of the earthquake being prepared - the weaker earthquake, the weaker ionosphere reaction. 
The Italian earthquakes are not that powerful and numerous as Japanese, however the last tragic events at L'Aquila on 6 April 2009 urgently demand to consider all available methods which could help in the earthquakes prediction. For this aim all the earthquakes with $\mathrm{M} \geq 5.5$ observed in Italy during 1979-2009 were analyzed using the method by Korsunova and Khegai (2006, 2008). On one hand the Italian earthquakes are less powerful compared to Japanese ones, on the other hand geographically this is different region and a priori it is not obvious whether similar quantitative relationships can be obtained for the Italian earthquakes. This is the aim of the present analysis, which seems to be important from practical point of view.

\section{Data analysis}

Initially all the earthquakes with magnitude $\mathrm{M}>5.0$ have been considered but we could not reveal significant precursors for weak events, therefore only strong earthquakes with $M \geq 5.5$ are analyzed in this paper. Overall 10 earthquakes with $M \geq 5.5$ (Table 1) have been registered during 19792009 (Catalogo, 2005). These are crustal earthquakes with the epicenter depth $<50 \mathrm{~km}$. Observations from the ionospheric station Rome (41.8 N; 12.5 E) were used in our analysis. Only hourly observations are available for the majority of cases. The distance $R$ from the ionosonde station to the epicenter calculated along the great-cycle path is given in Table 1 . The correction to $R$ for E-region heights is $<2 \mathrm{~km}$ for the selected events and it can be ignored. The epicenters are located at a distance $90-500 \mathrm{~km}$ to the north-east or to the south from Rome.

The earth crust structure in seismic areas is not uniform and the ionospheric response may be different in different directions (Sidorin, 1992). As we are unaware of the crust structure in the region in question, we confined our analysis with the earthquakes in the nearest to the epicenter zone ( $R \leq 140 \mathrm{~km}$ ), which took place to the north-east from Rome. For all these earthquakes Rome is located in the preparation zone according to the formula by Dobrovolsky et al. (1979). One may suppose that under the accepted limitations this formula for homogeneous media is valid for the selected earthquakes as well. On the other hand, we could not find any reliable precursors for the distant and relatively weak earthquakes given in Table 1. It should be also mentioned that according to Liu et al. (2006) only the earthquakes which were within the distance of $150 \mathrm{~km}$ and with $\mathrm{M} \geq 5.4$ produced significant effect in the F2-region. It should be stressed that the analysis of the earthquake precursors in the nearest to the epicenter zone is the most important from practical point of view.

Ionospheric observations for August-September 1979, April-May 1984, August-October 1997, and March-April 2009 have been analyzed to identify the precursors. According to Korsunova and Khegai (2008) the deviations in three
Table 1. The earthquakes with magnitude $M \geq 5.5$ registered in Italy during 1979-2009. Geographical coordinates of the earthquake epicenters and the distance $(R)$ from the Rome ionosonde are given.

\begin{tabular}{cccccc}
\hline $\begin{array}{c}\text { Date of the } \\
\text { earthquake }\end{array}$ & $\begin{array}{c}\mathrm{UT}, \\
\text { hour }\end{array}$ & $\mathrm{M}$ & $\begin{array}{c}R \\
\mathrm{~km}\end{array}$ & Lat & Lon \\
\hline 19 Sep 1979 & $21: 35$ & 5.6 & 112 & 42.7 & 13.1 \\
7 May 1984 & $17: 49$ & 5.9 & 133 & 41.7 & 14.1 \\
11 May 1984 & $10: 41$ & 5.7 & 133 & 41.7 & 14.1 \\
26 Sep 1997 & $00: 33$ & 5.6 & 137 & 43.0 & 12.9 \\
26 Sep 1997 & $09: 40$ & 5.8 & 137 & 43.0 & 12.9 \\
14 Oct 1997 & $15: 23$ & 5.5 & 140 & 43.0 & 13.0 \\
12 Apr 1998 & $10: 56$ & 5.6 & 494 & 46.28 & 31.57 \\
9 Sep 1998 & $11: 28$ & 5.6 & 392 & 40.07 & 15.95 \\
6 Sep 2002 & $01: 21$ & 5.6 & 403 & 38.38 & 13.65 \\
6 Apr 2009 & $01: 32$ & 5.8 & 90 & 42.3 & 13.3 \\
\hline
\end{tabular}

$h^{\prime} \mathrm{Es}, f b \mathrm{Es}$, and $f_{o \mathrm{~F}} 2$ ionospheric parameters should simultaneously satisfy the precursor selection criteria. The occurrence of abnormally high Es layer for $2-3 \mathrm{~h}$ is considered as a necessary condition for identification. The $h^{\prime}$ Es heights should exceed the corresponding background values by $\geq 10 \mathrm{~km}$. An increase of $f b$ Es and $f o \mathrm{~F} 2$ also for $2-3 \mathrm{~h}$ during the same day soon after the $h^{\prime}$ Es increase is considered as a sufficient condition for the precursor identification. The blanketing frequency $f b$ Es excess over the background value should be not less than $20 \%$. Electron concentration in the F2-layer is subjected to large and irregular variations, however an increase in $f \circ \mathrm{F} 2$ by $\geq 10 \%$ over the background level also for 2-3 $\mathrm{h}$ after the increases in $h^{\prime}$ Es and $f b$ Es should take place.

The analysis of ionospheric data on Rome for the earthquake preparation periods (Table 1) has required the specification of the earlier formulated criteria for the precursor identification. The observations in Rome show from time to time the occurrence of additional sporadic layers at F1layer heights (170-200) km mostly during morning and daytime hours. Although they are treated as Es, in fact they may be due to the wind shear in the meridional component of the neutral air wind velocity at F1-layer heights (Footitt et al., 1983). It was also shown that the electric field effect was very small and cannot be responsible for the formation of such sporadic layers. Moreover such layers exist more than 2-3 h (our criterion), i.e. they belong to other class of events. Therefore, such high sporadic layers were not considered in our analysis and we have confined ourselves with $40 \mathrm{~km} \geq \Delta h^{\prime} \mathrm{Es} \geq 10 \mathrm{~km}$. Normally foEs should be larger $f b \mathrm{Es}$, but the $f b \mathrm{Es}=f o \mathrm{Es}$ condition is accepted if only $f o \mathrm{~F} 2$ value is present in the ionogram.

Ionospheric data analysis comprises of some steps. At first the background $h^{\prime} \mathrm{Es}, f b \mathrm{Es}, f o \mathrm{~F} 2$ variations are calculated. They characterize the quiet time diurnal variations for the analyzed years and months. 27-day running medians 


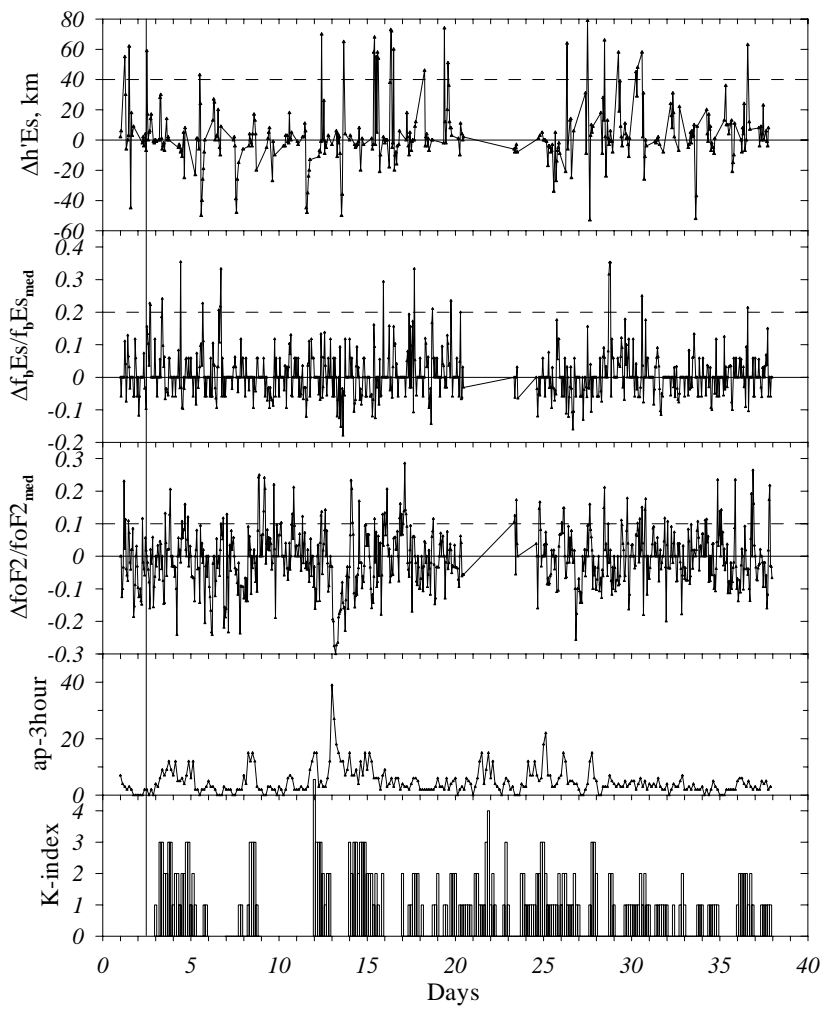

Fig. 1. Observed $\Delta h^{\prime} \mathrm{Es}, \delta f b \mathrm{Es}$, and $\delta f o \mathrm{~F} 2$ along with 3 -h ap and local K-indices for the whole preparation period (3 March 2009-6 April 2009) of the earthquake at L'Aquila. Dashes - the thresholds corresponding to the precursor selection criteria. Vertical solid line is the precursor date.

calculated over all quiet $(\mathrm{Ap} \leq 15)$ days are used as the background values. Then absolute $\Delta h^{\prime} \mathrm{Es}=h^{\prime} \mathrm{Es}-\left(h^{\prime} \mathrm{Es}\right)_{\mathrm{med}}$, $\Delta f_{b} \mathrm{Es}=f_{b} \mathrm{Es}-\left(f_{b} \mathrm{Es}\right)_{\mathrm{med}}, \Delta f o \mathrm{~F} 2=f o \mathrm{~F} 2-(f o \mathrm{~F} 2)_{\text {med }}$ and relative $\Delta f_{b} \mathrm{Es} /\left(f_{b} \mathrm{Es}\right)_{\text {med }}, \Delta f o \mathrm{~F} 2 /(f o \mathrm{~F} 2)_{\text {med }}$ deviations are calculated for all 24:00 UT moments of each day. After this the precursor is looked for in the period of 1.5 month preceding the earthquake date in accordance with the earlier formulated criteria. Middle-term earthquake precursors may occur up to 40 days in advance (Korsunova and Khegai, 2006; Hao et al., 2000) and this determines the time window selection of 1.5 month.

Sometimes earthquakes follow each other with a small time interval (see Table 1) and it may be problematic to correlate a particular precursor with a corresponding earthquake. In such cases the following rule is used. Under equal epicenter distances a precursor for an earthquake with larger magnitude occurs earlier and exhibits larger deviations in $h^{\prime}$ Es (Korsunova and Khegai, 2006). This enabled us to identify ionospheric precursors for all the earthquakes in question. Table 2 gives the revealed precursors with the corresponding parameters and the related earthquakes. For the 19 September 1979 event (Table 1) no precursors were found which would exactly correspond to our criteria (although they are
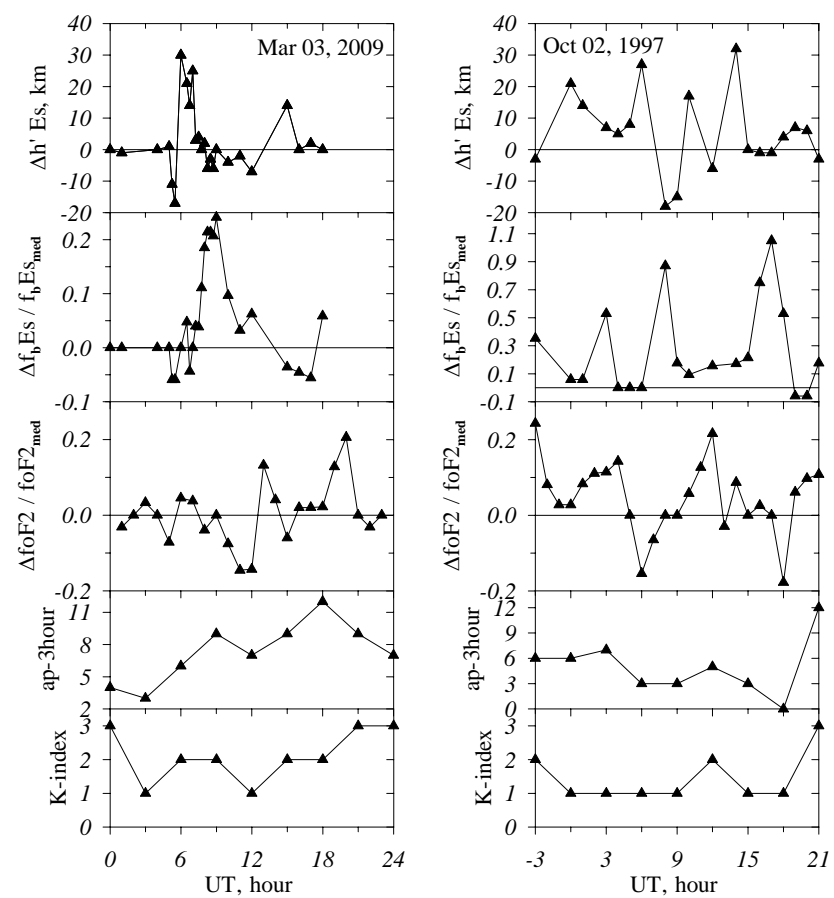

Fig. 2a. The precursors identification for the 6 April 2009 (left panel) and 14 October 1997 (right panel) earthquakes using observed $\Delta h^{\prime}$ Es, $\delta f b$ Es, and $\delta f o \mathrm{~F} 2$ variations. 3-h ap and local Kindices are given in lower panels.

close to our requirements). For this reason we have excluded this event from our analysis. It should be stressed that false precursors have not been found for the earthquakes in question.

Figure 1 gets an idea about the variations of the analyzed parameters for the whole 33-day preparation period of the 6 April 2009 earthquake at L'Aquila. The variations are given along with 3-h $a_{p}$ and local K-indices. The thresholds corresponding to our criteria are also shown in Fig. 1.

Although such data presentation may be interesting, it is not much informative to illustrate the precursor selection procedure. Therefore, $\Delta h^{\prime} \mathrm{Es}, \delta f b \mathrm{Es}$, and $\delta f o \mathrm{~F} 2$ variations along with 3-h $a_{p}$ and local K-indices for the precursor dates are given in Fig. 2a-c for the 6 analyzed events. In the case of the 6 April 2009 earthquake at L'Aquila 15-min observations are available and they give a more detail picture and normally only 15-min observations should be used for such analysis. Dealing with 1-h observations one may miss a real precursor for instance in the case of a 2-h upsurge in the analyzed parameters.

\section{Results}

Table 2 and Fig. 2a-c shows that the precursors in the Es parameters can be identified even under magnetically disturbed conditions. This is in agreement with the results by 
Table 2. Revealed ionospheric precursors and corresponding earthquakes. Lead times $\Delta T$ for the precursor occurrence and daily Ap indices are given as well.

\begin{tabular}{cccccccccccc}
\hline $\begin{array}{c}\mathrm{n} / \mathrm{n} \\
\text { precursor }\end{array}$ & $\begin{array}{c}\text { Date of the } \\
\text { hour }\end{array}$ & $\begin{array}{c}\mathrm{UT} \\
\text { pres }\end{array}$ & $\delta f b \mathrm{Es}$ & $\delta f o \mathrm{~F} 2$ & $\begin{array}{c}\Delta T \\
\text { days }\end{array}$ & Ap & $\begin{array}{c}\text { Date of the } \\
\text { earthquake }\end{array}$ & $\begin{array}{c}\mathrm{UT} \\
\text { hour }\end{array}$ & $\begin{array}{c}\mathrm{M} \\
\mathrm{km}\end{array}$ \\
\hline 1 & 4 Apr 1984 & 00:00-01:00 & 37 & 0.25 & 0.30 & 33.8 & 84 & 7 May 1984 & $17: 49$ & 5.9 & 133 \\
2 & 24 Apr 1984 & $01: 00-02: 00$ & 27 & 0.82 & 0.16 & 17.4 & 6 & 11 May 1984 & $10: 41$ & 5.7 & 133 \\
3 & 8 Sep 1997 & $05: 00-06: 00$ & 19 & 0.61 & 0.16 & 17.8 & 12 & 26 Sep 1997 & $00: 33$ & 5.6 & 137 \\
4 & 2 Sep 1997 & 14:00-15:00 & 28 & 0.79 & 0.16 & 23.8 & 4 & 26 Sep 1997 & $09: 40$ & 5.8 & 137 \\
5 & 2 Oct 1997 & $00: 00-01: 00$ & 21 & 0.87 & 0.22 & 12.6 & 5 & 14 Oct 1997 & $15: 23$ & 5.5 & 140 \\
6 & 3 Mar 2009 & $06: 00-07: 00$ & 30 & 0.24 & 0.21 & 33.8 & 7 & 6 Apr 2009 & $01: 32$ & 5.8 & 90 \\
\hline
\end{tabular}


Fig. 2b. Same as Fig. 2a, but for the 26 September 1997 at 09:40 UT (left panel) and 26 September 1997 at 00:33 UT (right panel) earthquakes.

Maksyutin et al. $(2001,2005)$ who have shown that $\delta$ foEs $<0$ for disturbed conditions. As $f b$ Es is related to foEs we should conclude that such reaction to geomagnetic activity is opposite to what is used in our method - we consider only increases in $f b$ Es. According to their statistical analysis some foEs increase $<20 \%$ takes place on the second day after the geomagnetic disturbance and only in winter under solar minimum. According to our criteria we consider only the cases with $f b \mathrm{Es} \geq 20 \%$. The geomagnetic activity effects can be anticipated in the $f o \mathrm{~F} 2$ variations, but this relationship is known to be not simple: for instance compare $\delta f o \mathrm{~F} 2$ values for quiet and disturbed conditions in Table 2 and Fig. 2 . Therefore, the criteria formulated earlier should be applied independently on the geomagnetic activity level.
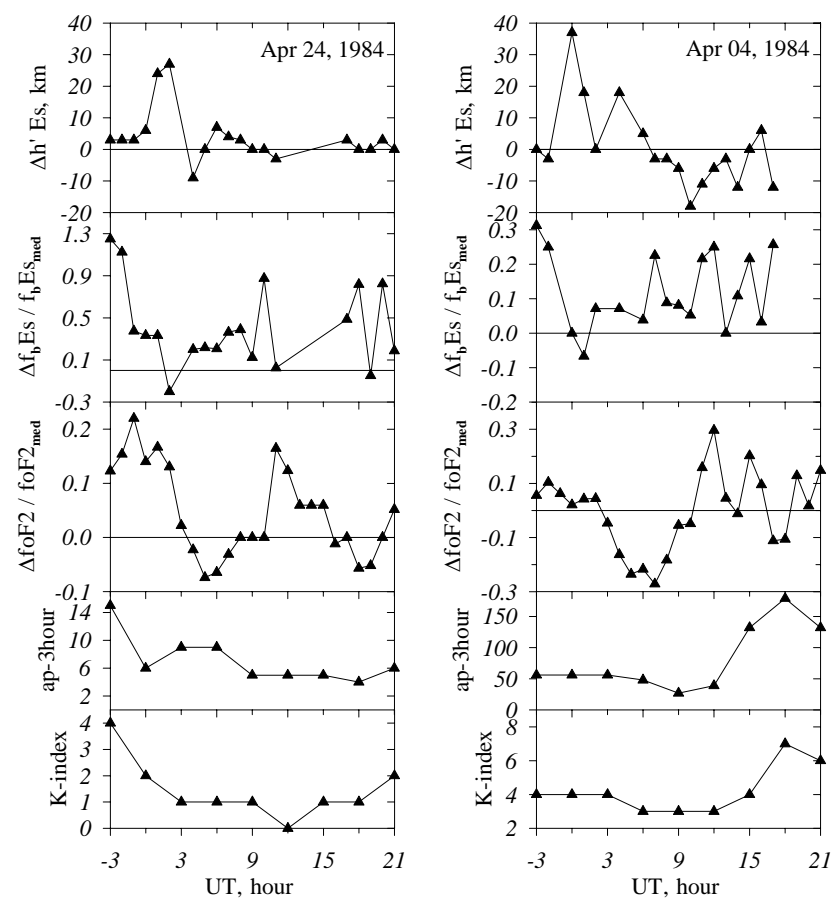

Fig. 2c. Same as Fig. 2a, but for the 11 May 1984 (left panel) and 7 May 1984 at 00:33 UT (right panel) earthquakes.

As it was mentioned earlier a distinctive feature of the applied method is using of three parameters simultaneously (2-3) h splashes in $\Delta h^{\prime} \mathrm{Es}, \delta f b \mathrm{Es}$, and $\delta f o \mathrm{~F} 2$ above the corresponding thresholds should take place within one day and they should follow each other. Therefore, using only the deviations in $f o \mathrm{~F} 2$ as suggested in some publications, it is embarrassing to identify the precursor with such lead times (see Table 2). Moreover, the deviations in $f \circ \mathrm{F} 2$ are not large (16$30 \%$ ) and they cannot be considered as independent precursors. Thus, if the Es-layer parameter observations are unavailable, it is impossible to identify the middle-term precursors in the F2-layer even in the nearest to the epicenter zone for the earthquakes with $\mathrm{M} \geq 5.5$. 




Fig. 3. The observed dependencies for $\log (\Delta T)$ and $\log (\Delta T \cdot R)$ on the earthquake magnitude. Correlation coefficients $(r)$ and standard deviations (SD) of the points from the regression line are given. Notice that inclusion of the epicenter distance $R$ improves to some extent the dependence (bottom panel). Dashes are \pm SD. Both dependences are significant at $99 \%$ confidence level.

The results of Table 2 show that under equal epicenter distances the larger the magnitude of the earthquake, the larger $h^{\prime}$ Es deviation (cf. nn $1-2$ and 3-4). The lead time is also larger for stronger earthquakes. These features are typical of the middle-term precursors (Gufeld and Gusev, 1998).

The $\Delta h^{\prime} \mathrm{Es}, \delta f b \mathrm{Es}$, and $\delta f o \mathrm{~F} 2$ variations used for the precursors identification are shown in Fig. 2a-c for the 6 selected events (Table 2). Five of 6 precursor dates were magnetically quiet according to both $a_{p}$ and local K-indices variation, while the day 4 April 1984 was very disturbed (Fig. 2c right panel), however the deviations in the analyzed parameters are in the same limits. This confirms the earlier made conclusion about the possibility to use geomagnetically disturbed days for the precursor identification. It is seen that using 2-3 h splashes in $\Delta h^{\prime} \mathrm{Es}, \delta f b \mathrm{Es}$, and $\delta f o \mathrm{~F} 2$ following each other within one day as a criterion, it is possible to identify the precursor.

There are dependencies for middle-term precursors relating the lead time $\Delta T$ with the earthquake magnitude $\mathrm{M}$ and the epicenter distance $R$ (Sidorin, 1992; Korsunova and Khe-



Fig. 4. The observed dependences for $\log \left(\Delta h^{\prime}\right.$ Es $)$ and $\log \left(\Delta h^{\prime}\right.$ Es. $\left.R\right)$ on the earthquake magnitude. Correlation coefficients $(r)$ and standard deviations (SD) are also given. Notice that unlike the $\Delta T$ case the inclusion of the epicenter distance $R$ does not improve the dependence (bottom panel). Dashes are \pm SD. The upper dependence is significant at the $99 \%$ confidence level, while the lower dependence is insignificant.

gai, 2006). They indicate the process of spreading the disturbance from the epicenter towards periphery. Such dependences are given in Fig. 3 for the earthquakes in question (Table 2). The upper panel gives the dependence of lead time on the earthquake magnitude. The lower panel gives the same dependence, but for the product $(\Delta T \cdot R)$. It should be stressed that in the concept by Korsunova and Khegai (2006, 2008) $R$ really depends on the earthquake magnitude $M$ for $R$ within the preparation zone, therefore there is sense to consider two dependencies separately. The inclusion of the epicenter distance to the dependence is seen to improve the statistics to some extent: the correlation coefficient $r=0.943$ compared to 0.929 and the standard deviation $\mathrm{SD}=0.046$ instead of 0.064 in the first case. Both dependencies are statistically significant at the $99 \%$ confidence level according to Fisher F-criterion. A modest effect of the $R$ inclusion is due to small range of $R$ variations - all $R$ values are within 133$140 \mathrm{~km}$ with the only exception on 3 March 1990 (Table 2). But these two points with $R=5.8$ are seen to become much closer in the bottom panel compared to the top one. 
Table 3. The standard errors associated to the regressions (1-3) coefficients.

\begin{tabular}{ccc}
\hline Equation & First coefficient & Second coefficient \\
\hline$(1)$ & $1.091 \pm 0.22$ & $-4.897 \pm 1.25$ \\
$(2)$ & $0.886 \pm 0.15$ & $-1.626 \pm 0.83$ \\
$(3)$ & $0.672 \pm 0.13$ & $-2.422 \pm 0.76$ \\
\hline
\end{tabular}

Similar dependencies for $\Delta h^{\prime}$ Es and $\left(\Delta h^{\prime}\right.$ Es $\left.\cdot R\right)$ are given in Fig. 4. The correlation coefficient between $\log \left(\Delta h^{\prime}\right.$ Es $)$ and $\mathrm{M}$ is 0.929 under the $99 \%$ confidence level. But unlike the previous case (Fig. 3) the inclusion of the epicenter distance does not improve the dependence on $\mathrm{M}$. The correlation coefficient for $\log \left(\Delta h^{\prime}\right.$ Es. $\left.R\right)$ drops down to 0.659 with the confidence level $<90 \%$ according to Fisher criterion. No significant relationship between $f b$ Es and the earthquake magnitude $\mathrm{M}$ was found. Therefore, only the relationships for $\log (\Delta T)$, $\log (\Delta T \cdot R)$, and $\log \left(\Delta h^{\prime}\right.$ Es $)$ can be used for practice:

$\log (\Delta T)=1.091 \mathrm{M}-4.897$

$\log (\Delta T \cdot R)=0.886 \mathrm{M}-1.626$

$\log \left(\Delta h^{\prime} \mathrm{Es}\right)=0.672 \mathrm{M}-2.422$

The standard errors associated to the regressions (1-3) coefficients are given in Table 3. Due to small statistics (only 6 events) the uncertainty in coefficients is pretty large however the obtained expressions are similar to those obtained by other researches. Using Es layer parameter observations at Ashkhabad (Middle Asia) for the earthquakes with moderate magnitudes, Korsunova (2004) has obtained:

$\log (\Delta T \cdot R)=0.74 \mathrm{M}-0.96$

Korsunova and Khegai (2006) for 33 powerful earthquakes with $M \geq 6$ that occurred in the region of Kokubunji station in 1985-2000, obtained the dependence:

$\log (\Delta T \cdot R)=1.14 \mathrm{M}-4.72$

Ground observations of various geophysical parameters for a number of earthquakes with $M=4-8$ (Sidorin, 1992) resulted in the following dependence:

$\log (\Delta T \cdot R)=0.72 \mathrm{M}-0.72$

A qualitative agreement is seen for the dependences $(2,4$, $5,6)$ obtained using both ground and ionospheric precursors. The similarity of the dependencies obtained in different parts of the world tells us about the uniformity of the processes during the earthquake preparation period and the perspective of the proposed method to use the observed Es-layer parameters as the ionospheric precursor.

\section{Forecast possibilities}

An important result of our analysis is quantitative expressions (1-3) which relate the earthquake magnitude and the epicenter distance with observed $h^{\prime}$ Es variations. In principle such expressions could be used for prediction purposes to determine the magnitude $\mathrm{M}$ and lead time $\Delta T$ of future earthquake. As all the earthquakes in the vicinity of Rome take place practically in one and the same area, the epicenter distance $R$ may be considered as a known parameter. However large uncertainty (due to small statistics) of the regression coefficients (Table 3 ) does not allow us to make such a prediction with an acceptable accuracy. For instance, the magnitude $\mathrm{M}$ can be estimated from Eq. (3) with $\Delta \mathrm{M}=2.3$ and this is not acceptable for any practical applications.

Another aspect of the earthquakes prediction is false precursors. It is obvious that dependences similar to (1-3) may have any practical sense if only the probability of false precursors is not high. A special analysis has been undertaken to clarify this question. We have checked two years 1997 and 1984 when real strong earthquakes took place (Table 1) and one "pure" of strong earthquakes year 2002 when all observed events in the vicinity of Rome $(R<150 \mathrm{~km})$ had the magnitude $\mathrm{M}<4.0$. The $\Delta h^{\prime} \mathrm{Es}, \delta f_{b} \mathrm{Es}$, and $\delta f o \mathrm{~F} 2$ deviations were calculated for 24:00 UT moments of all days and all months of the years. The calculated values were analyzed for ionospheric precursors in accordance with our criteria. The list of the revealed false precursors is given in Table 4 along with calculated $\mathrm{M}, \Delta T, R$ values using the relationships (1-3). Only the characteristics of strong $(M \geq 5.5)$ expected events are listed in Table 4 . The undertaken analysis has shown that false precursors really exist in all three years considered. They are seen not to be numerous, but their number is comparable to the number of real earthquakes (Table 2) and they are not distinguished from real precursors. One may think that the false precursors are related to the same earthquake preparation process which however has not resulted in real earthquake for unknown reasons.

\section{Discussion}

The undertaken consideration has shown that the approach proposed by Korsunova and Khegai $(2006,2008)$ can be applied as well for weaker earthquakes with $5.5 \leq \mathrm{M}<6.0$ taking place in Italy in the vicinity of Rome. The simultaneous deviations in $\Delta h^{\prime} \mathrm{Es}, \delta f b \mathrm{Es}$, and $\delta f o \mathrm{~F} 2$ above the corresponding thresholds for $2-3 \mathrm{~h}$ following each other within one day can be related by logarithmic dependences with the earthquake magnitude and the epicenter distance. Despite few cases available the obtained dependences (1-3) for $\log (\Delta T)$, $\log (\Delta T \cdot R)$, and $\log \left(\Delta h^{\prime}\right.$ Es $)$ versus the earthquake magnitude are statistically significant at the $99 \%$ confidence level and may be considered as having real physical sense. The most interesting is the $\log (\Delta T \cdot R)$ dependence which tells 
Table 4. Revealed false ionospheric precursors for three years 1997, 1984, 2002 along with calculated M, $\Delta T, R$ values using the relationships (1-3). Only expected events with $M \geq 5.5$ are listed.

\begin{tabular}{ccccccccc}
\hline $\mathrm{n} / \mathrm{n}$ & $\begin{array}{c}\text { Date of the false } \\
\text { precursor }\end{array}$ & $\begin{array}{c}\mathrm{UT} \\
\text { hour }\end{array}$ & $\Delta h^{\prime}$ Es & $\delta f b \mathrm{Es}$ & $\delta f \circ \mathrm{F} 2$ & $\mathrm{M}$ & $\begin{array}{c}\Delta T \\
\text { days }\end{array}$ & $\begin{array}{c}R \\
\mathrm{~km}\end{array}$ \\
\hline 1 & 21 Apr 1997 & $06: 00-08: 00$ & 28 & 0.58 & 0.33 & 5.8 & 24 & 124 \\
2 & 20 May 1997 & $02: 00-03: 00$ & 25 & 0.92 & 0.27 & 5.7 & 20 & 128 \\
3 & 22 Nov 1997 & $13: 00-14: 00$ & 30 & 0.21 & 0.71 & 5.8 & 27 & 121 \\
4 & 2 Feb 1984 & $10: 00-11: 00$ & 24 & 0.48 & 0.23 & 5.7 & 19 & 130 \\
5 & 19 Mar 1984 & $16: 00-17: 00$ & 39 & 0.25 & 0.17 & 6.0 & 41 & 112 \\
6 & 20 Sep 1984 & $09: 00-10: 00$ & 24 & 0.53 & 0.12 & 5.7 & 19 & 130 \\
7 & 7 Aug 2002 & $05: 00-06: 00$ & 22 & 0.30 & 0.22 & 5.6 & 16 & 134 \\
8 & 21 Sep 2002 & $07: 00-09: 00$ & 30 & 0.437 & 0.18 & 5.8 & 27 & 122 \\
9 & 27 Dec 2002 & $07: 00-08: 00$ & 31 & 0.41 & 0.12 & 5.8 & 28 & 120 \\
\hline
\end{tabular}

about a decrease of the lead time for the precursor occurrence for larger epicenter distance, that is the seismo-ionospheric disturbance spreads from the epicenter area towards periphery. Earlier similar dependencies were obtained from analyses of geophysical parameter variations at the ground level (Sidorin, 1992). The dependence for $\log (\Delta T)$ directly relates the lead time with the earthquake magnitude, that is the stronger the earthquake the larger lead time for the precursor to occur at a given distance from the epicenter. Large lead times for the precursor occurrence (up to 34 days for $\mathrm{M}=5.8$ 5.9, Table 2) tells about a prolong preparation period. Similar conclusions were obtained from electric field observations in China (Hao et al., 2000). The observed lead time varied from 2 to 40 days for 45 earthquakes with $M=3.2-6.4$. Keeping in mind that atmospheric electric fields above the preparation zone and the anomalies in the ionospheric parameters are the links of one chain (Pulinets et al., 1998), this coincidence is hardly random. Therefore, this result as well as the results by Korsunova and Khegai $(2006,2008)$ may be considered as an important step towards the understanding the physical mechanism of the seismo-ionospheric relationships.

A theory of the earthquake preparation based on taking into account the electromagnetic processes in the lithosphere-atmosphere-ionosphere system (Kim et al., 1994; Pulinets et al., 1998; Sorokin et al., 2006), implies a formation of a sporadic E-layer with large electron concentration at the heights of $120-140 \mathrm{~km}$ above the earthquake preparation zone. Long-living ( $\Delta t \approx 2-3 \mathrm{~h}$ ) sporadic Es layers revealed and used in our analysis occur at heights by $\geq 10 \mathrm{~km}$ higher than normal Es for corresponding geophysical conditions. Their formation is accompanied by an increase in $f b \mathrm{Es}$ and $f_{o} \mathrm{~F} 2$.

Our method to identify a precursor uses three parameters simultaneously, the $\Delta h^{\prime}$ Es being the main, and this is a principle difference from other methods based on one ionospheric parameter - foF2, for instance Liu et al. (2006); Dabas et al. (2007). Although the authors try to eliminate the geomagnetic activity effects from their analyses, one should keep in mind that $f o \mathrm{~F} 2$ is a very variable parameter affected both from above (solar EUV, magnetospheric and dynamo electric fields, IMF changing thermospheric circulation and neutral composition, TADs etc.) and from below (planetary and gravity waves, neutral gas vertical motion and eddy diffusion changing thermospheric neutral composition, tropospheric electric fields not necessary related to seismic processes). Therefore, besides the geomagnetic activity effects there are many other reasons for $f o \mathrm{~F} 2$ variations. The morphology of the F2-layer perturbations not related to geomagnetic activity (so called Q-disturbances) can be found in Mikhailov et al. (2004), Depueva et al. (2005). Equatorial and low-latitude F2-region considered by Dabas et al. (2007) is strongly affected by electric fields which exhibit large variability even under geomagnetically quiet conditions (e.g. counter electrojet). Therefore $f o \mathrm{~F} 2$ is a very "inconvenient" ionospheric parameter for the role of an earthquake precursor. For this reason in our method $f_{o} \mathrm{~F} 2$ is considered as a parameter whose variations are taken into account only along with Es parameter variations, but (2-3)-h deviations in $\Delta f o \mathrm{~F} 2$ above the background level should take place as well. For this reason we have excluded the 19 September 1979 event from our analysis as we have failed to find the deviations in all three parameters exactly corresponding to our criteria.

The final goal of such considerations is to find reliable earthquake precursors. Unfortunately there are not too many publications which can propose any recommendations for practical use. The results by Korsunova and Khegai (2006, 2008) as well as the present analysis show a way how routine ionospheric observations of Es and F2 layer parameters in the seismic regions could be used to predict the characteristics of future earthquakes. However due to small number of events (fortunately for Italy!) the statistic reliability of the regression coefficients is not very high and prevents us from making any quantitative forecast. 
Another problem of real forecast is false precursors. Although they are not numerous (Table 4), but they exhibit the same features as real ones and cannot be distinguished in the monitoring process. One may suppose that the false precursors are related to the same process of electric fields penetration from below, but these fields either are not related to the earthquake preparation process or the process has not resulted in real earthquake for unknown reasons. Anyway the question of false precursors needs further consideration keeping in mind its practical importance. In the framework of the proposed mechanism the disturbance spreads from the epicenter towards periphery. An installation of a couple of ionosondes in line from the seismic zone (in the case of Italy its location is known) may help capture this spreading process and separate real precursors from false ones if they have different origin.

\section{Conclusions}

The results of our analysis may be summarized as follows.

1. An earlier proposed by Korsunova and Khegai (2006, 2008) approach to identify the ionospheric precursors for powerful crustal earthquakes using sporadic Es and regular F2-layer parameter observations was shown to be applicable for moderate earthquakes with $5.5 \leq \mathrm{M}<6.0$ observed in Italy.

2. The observed ionospheric precursors result in the dependence relating the lead time $\Delta T$ with the earthquake magnitude $\mathrm{M}$ and the epicenter distance $R$. The obtained dependence is statistically significant at the $99 \%$ confidence level and it looks similar to earlier obtained for more powerful Japanese earthquakes. The dependence indicates the process of spreading the disturbance from the epicenter towards periphery during the earthquake preparation process. Large lead times for the precursor occurrence (up to 34 days for $M=5.8-5.9$ ) tells about a prolong preparation period.

3. The similarity of the dependencies obtained in different parts of the world tells about the uniformity of the processes during the earthquake preparation period both for powerful and moderate earthquakes.

4. The revealed quantitative relationships between the earthquake parameters and their ionospheric precursors should be considered as an important step towards the mechanism of the seismo-ionospheric relations distinguishing the present approach from mere statistical ones widely used in seismo-ionospheric analyses.

Acknowledgements. The authors thank Andrea Malagnini for the ionograms scaling and the Geomagnetism Unit of INGV for providing $\mathrm{k}$-indices. This work was in part supported by the Russian Foundation for Basic Research under Grant 09-05-00240-a.
Topical Editor M. Pinnock thanks T. Ondoh and another anonymous referee for their help in evaluating this paper.

\section{References}

Bolt, B. A.: Earthquake, 4th ed., edited by: Freeman, W. H., New York, 1999.

Bortnik, J., Cutler, J. W., Dunson, C., and Bleier, T. E.: The possible statistical relation of Pc1 pulsations to Earthquake occurrence at low latitudes, Ann. Geophys., 26, 2825-2836, 2008, http://www.ann-geophys.net/26/2825/2008/.

Catalogo della Sismicita' Italiana CSI 1.1, CNR, INGV, CSTI 1.0 Working Group, 2005.

Dabas, R. S., Das, R. M., Sharma, K., and Pillai, K. G. M.: Ionospheric precursors observed over low latitudes during some of the recent major earthquakes, J. Atmos. Solar-Terr. Phys., 69, 1813-1824, 2007.

Depueva, A. Kh., Mikhailov, A. V., and Depuev, V. Kh.: Quiet time F2-layer disturbances at geomagnetic equator, Int. J. Geomag. Aeronom, 5, 1-11, GI3001, doi:10.1029/2004GI000071, 2005.

Dobrovolsky, I. R., Zubkov, S. I., and Myachkin, V. I.: Estimation of the size of earthquake preparation zones, Pageoph., 10251044, 1979.

Footitt, R. J., Bailey, G. J., and Moffett, R. J.: Ion transport in the mid-latitude F1-region, Planet Space Sci., 31, 671-687, 1983.

Freund, F.: Time resolved study of charge generation and propagation in igneous rocks, J. Geophys. Res., 105, 11001-11019, 2000.

Gufeld, I. L. and Gusev, G. A.: Recent state of earthquake predictions (Is there any way out of the impasse?), in: Short-term prediction of catastrophic earthquakes using radar ground-space methods, edited by: Strakhov, V. N. and Liperovsky, V. A., Moscow , 7-25, 1998.

Hao, J., Tianming, T., and Li, D.: Progress in the research of atmospheric electric field anomaly as an index for short-impending prediction of earthquakes, J. Earthquake Prediction Res., 8, 241255, 2000.

Hayakawa, M.: Atmospheric and ionospheric electromagnetic phenomena with earthquakes, Terra Science Publishing Co., Tokyo, 1999.

Hayakawa, M. and Molchanov, O. A.: Seismo electromagnetic, lithospheric-atmospheric-ionospheric coupling, Terra Science Publishing Co., Tokyo, 2002.

Hayakawa, M., Pulinets, S., Parrot, S., and Molchanov, O. A.: Recent progress in seismo-electromagnetics and related phenomena, Phys. Chem. Earth, Parts A/B/C/, 31(4-9), 129-496, 2006.

Hobara, Y. and Parrot, M.: Ionospheric perturbations linked to a very powerful seismic event, J. Atmos. Solar-Terr. Phys., 67, 677-685, doi:10.1016/j.jastp.2005.02.006, 2005.

Kim, V. P., Khegai, V. V., and Illich-Svitych, P. V.: Probability of formation of a metallic ion layer in the nighttime midlatitude ionospheric E-region before strong earthquakes, Geomag. Aeronom., 33, 114-119, 1993 (in Russian).

Kim, V. P., Khegai, V. V., and Illich-Svitych, P. V.: On one possible ionospheric precursor of earthquakes, Phys. Solid Earth, 30, 223-226, 1994 (in Russian).

Korsunova, L. P.: Precursor effects in the sporadic Es for crustal earthquakes in Japan and Middle Asia, in: Solar-Terrestrial relationships and electromagnetic precursors of the earthquakes, 
III International Conference, Paratunka, 16-21 August 2004, pp. 65-70, 2004 (in Russian).

Korsunova, L. P. and Khegai, V. V.: Medium-term ionospheric precursors to strong earthquakes, Int. J. Geomagn. Aeron., 6, GI3005, doi:10.1029/2005GI000122, 2006.

Korsunova, L. P. and Khegai, V. V.: Analysis of seismo-ionospheric disturbances at the chain of Japanese stations for vertical sounding of the ionosphere, Geomagn. Aeronom., 48, 392-399, 2008.

Liu, J. Y., Chen, Y. I., Chuo,Y. J., and Chen, C. S.: A statistical investigation of pre-earthquake ionospheric anomaly, J. Geophys. Res., 111, A05304, doi:10.1029/2005JA011333, 2006.

Maekawa, S., Horie, T., Yamauchi, T., Sawaya, T., Ishikawa, M., Hayakawa, M., and Sasaki, H.: A statistical study on the effect of earthquakes on the ionosphere, based on the subionospheric LF propagation data in Japan, Ann. Geophys., 24, 2219-2225, 2006, http://www.ann-geophys.net/24/2219/2006/.

Maksyutin, S. V., Fahrutdinova, A. N., and Sherstyukov, O. N.: Es layer and dynamics of neutral atmosphere during the periods of geomagnetic disturbances, J. Atmos. Solar-Terr. Phys., 63, 545549, 2001

Maksyutin, S. V. and Sherstyukov, O. N.: Dependence of Esporadic layer response on solar and geomagnetic activity variations from its ion composition, Adv. Space Res., 35, 1496-1499, 2005.

Mazzarella, A. and Palumbo, A.: Solar, geomagnetic and seismic activity, Il Nuovo Cimento, Ser. 11C, 353-364, 1988.

Mikhailov, A. V., Depueva, A. Kh., and Leschinskaya, T. Yu.: Morphology of quiet time F2-layer disturbances: High and lower latitudes, Int. J.Geomag. Aeronom, 5, 1-14, GI1006, doi:10.1029/2003GI000058, 2004.

Ondoh, T.: Ionospheric disturbances associated with great earthquake of Hokkaido southwest coast, Japan of July 12, 1993, Phys. Earth Planet. Interiors, 105, 261-269, 1998.

Ondoh, T.: Seismo-ionospheric phenomena, Adv. Space Res., 26(N8), 1267-1272, 2000.
Ondoh, T.: Anomalous sporadic-E layers observed before M 7.2 Hyogo-ken Nanbu earthquake; Terrestrial gas emanation model, Adv. Polar Upper Atmos. Res., 17, 96-108, 2003.

Ondoh, T.: Investigation of precursory phenomena in the ionosphere, atmosphere and groundwater before large earthquakes of M>6.5, Adv. Space Res., 43, 214-223, 2009.

Ondoh, T. and Hayakawa, M.: Synthetic study of precursory phenomena of the M7.2 Hyogo-ken Nanbu earthquake, Phys. Chem. Earth, 31, 378-388, 2006.

Pulinets, S. A., Khegai, V. V., Boyarchuk, K. A., and Lomonosov, A. M.: Atmospheric electric field as a source of ionospheric variability, Physics-Uspekhi, 41, 515-522, 1998.

Sharma, D. K., Israil, M., Chand, R., Rai, J., Subrahmanyam, P., and Garg, S. C.: Signature of seismic activities in the F2 region ionospheric electron temperature, J. Atmos. Solar-Terr. Phys., 68, 691-696, 2006.

Silina, A. S., Liperovskaya, E. V., Liperovsky, V. A., and Meister, C.-V.: Ionospheric phenomena before strong earthquakes, Nat. Hazards Earth Syst. Sci., 1, 113-118, 2001, http://www.nat-hazards-earth-syst-sci.net/1/113/2001/.

Sidorin, A. Ya.: Earthquake precursors, Nauka, M., 1992 (in Russian).

Sorokin, V. M., Yaschenko, A. K., and Hayakawa, M.: Formation mechanism of the lower ionospheric disturbances by the atmospheric electric current over a seismic region, J. Atmos. Sol.-Terr. Phys., 68, 1260-1268, 2006.

Strakhov, V. N. and Liperovsky, V. A. (Eds.): Short-term forecast of catastrophic earthquakes using radiophysical ground-based and space methods, Inst. Earth Phys., Moscow, 1999 (in Russian).

Trigunait, A., Parrot, M., Pulinets, S., and Li, F.: Variations of the ionospheric electron density during the Bhuj seismic event, Ann. Geophys., 22, 4123-4131, 2004, http://www.ann-geophys.net/22/4123/2004/.

Yanben, H., Zengjian, G., Jinbing, W., and Lihua, M.: Possible triggering of solar activity to big earthquakes $(\mathrm{Ms} \geq 8)$ in faults with near west-east strike in China, Science in China, Ser. G Physics, Mech. Astron., 47, 173-181, 2004. 